\section{Letter to the Editor}

Clinical Microbiology

Ann Lab Med 2022;42:370-372

https://doi.org/10.3343/alm.2022.42.3.370

Check tor
upodates

ISSN 2234-3806 elSSN 2234-3814

\title{
Invasive Hormographiella aspergillata Infection Identified Using DNA Sequencing
}

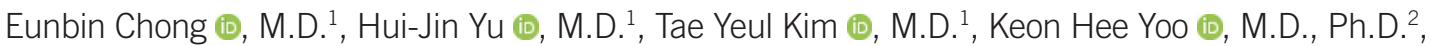

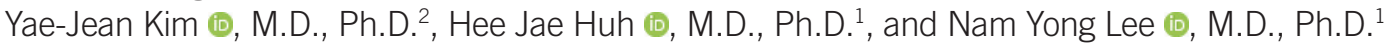 \\ Departments of ${ }^{1}$ Laboratory Medicine and Genetics and ${ }^{2}$ Pediatrics, Samsung Medical Center, Sungkyunkwan University School of Medicine, Seoul, Korea
}

\section{Dear Editor,}

Hormographiella aspergillata is a filamentous basidiomycete first reported as a human pathogen in 1971 [1]. Its anamorph form, Coprinopsis cinerea, grows in the fecal material of cows and horses. A few cases of serious $H$. aspergillata infections have been documented in immunocompromised patients, making it an opportunistic pathogen [2-6]. Although molecular diagnostic tools have been applied to identify $H$. aspergillata infections, directly performing DNA sequencing on culture-negative tissues is rare $[7,8]$. Here, we described a case of invasive pulmonary H. aspergillata infection and the usefulness of DNA sequencing performed on culture-negative specimens to identify the rare fungal pathogen. The study was approved by the Institutional Review Board of Samsung Medical Center, Seoul, Korea (approval number: 2021-06-202), and the requirement of informed consent was waived.

A 13-year-old female with relapsed T-cell acute lymphoblastic leukemia (T-ALL) was admitted to the pediatric hematology department of Samsung Medical Center in August 2020 to receive chemotherapy for five days. She was diagnosed as having T-ALL two years earlier and had received allogeneic peripheral blood stem cell transplantation twice. The leukemia relapsed four months after the second transplantation; She underwent chemotherapy, including clofarabine, cytarabine, cyclophosphamide, and eto- poside, soon after admission. On day 17, the patient developed neutropenic fever with a temperature of $38.3^{\circ} \mathrm{C}$, C-reactive protein level of $220.4 \mathrm{mg} / \mathrm{L}$ (reference range, $0-5.0 \mathrm{mg} / \mathrm{L}$ ), and absolute neutrophil count of $0.0 \times 10^{9} / \mathrm{L}$. Three pairs of aerobic and anaerobic blood cultures were collected, and an empirical antibiotic therapy was initiated with meropenem and teicoplanin (105 mg/kg/day and $9 \mathrm{mg} / \mathrm{kg} /$ day, respectively). The antibiotic drugs were later switched to vancomycin $(60 \mathrm{mg} / \mathrm{kg} / \mathrm{day})$ when the methicillin-resistant Staphylococcus haemolyticus was detected in the blood culture. Empiric antifungal agent caspofungin (1.2 $\mathrm{mg} / \mathrm{kg} /$ day) was administered for the persistent neutropenic fever.

On day 30, the patient developed chest pain in the right axillary area. A chest $\mathrm{x}$-ray showed an opaque lesion in the right middle lung field, and a computed tomography (CT) scan revealed a dense consolidation in the pleura of the right lobe and anterior chest wall, suggesting an invasive fungal infection (Fig. 1).

As mucormycosis was suspected based on the CT scan, liposomal amphotericin B, instead of caspofungin, was administered. Biopsy of the infected lung tissue was performed, and the microscopic examination of the lung tissue revealed the presence of septate hyphae with multi-branching (Fig. 2).

Microbial cultures and ribosomal DNA (rDNA) targeted sequencing were performed on the lung tissue and pleural fluid
Received: July 25, 2021

Revision received: August 19, 2021

Accepted: November 29, 2021

Corresponding author: Hee Jae Huh, M.D., Ph.D.

Department of Laboratory Medicine and Genetics, Samsung Medical Center, Sungkyunkwan University School of Medicine, 81 Irwon-ro, Gangnam-gu, Seoul 06351, Korea

Tel: +82-2-3410-1836, Fax: +82-2-3410-2719,

E-mail: pmhhj77@gmail.com 


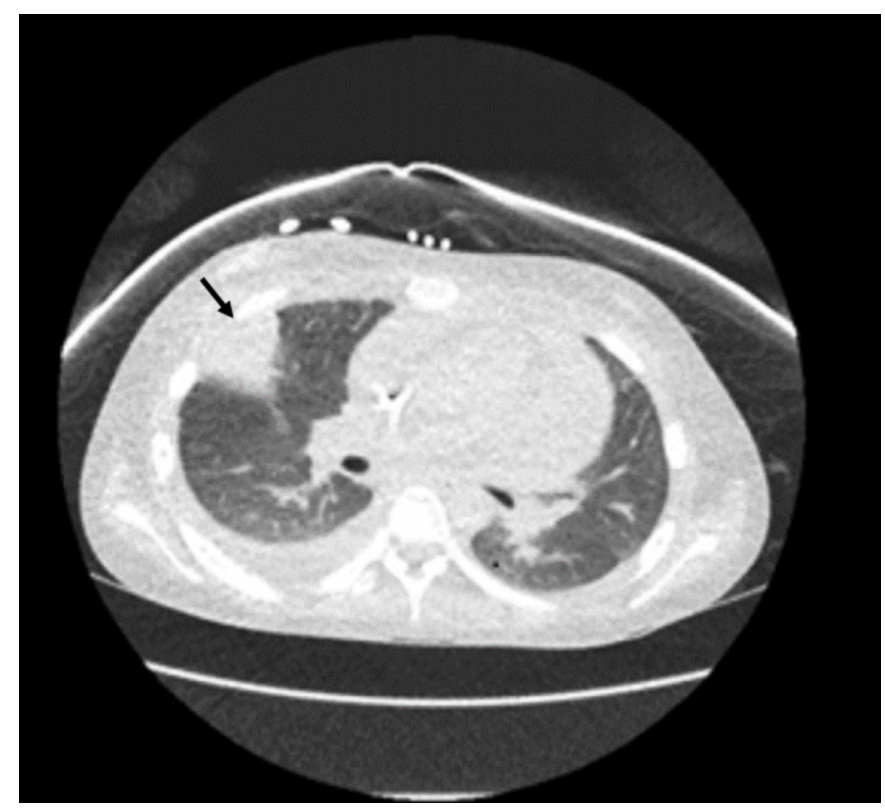

Fig. 1. Computed tomography scan showing lung infiltrate within the pleura of the right lobe and anterior chest wall (black arrow).

specimens collected on day 33. Cultures on Sabouraud dextrose agar plates incubated for three weeks remained negative. We extracted genomic DNA from the lung tissue and pleural fluid specimens and performed Sanger sequencing of the D1/ D2 and internal transcribed spacer (ITS) regions of the 28S subunit. The D1/D2 region was amplified for both specimens, but amplification of the ITS region was only observed for the lung tissue specimen. On comparing the sequencing results against the GenBank database using the basic local alignment search tool (https://blast.ncbi.nlm.nih.gov/Blast.cgi) algorithm, the D1/ D2 sequences of both specimens exhibited 100\% identity (563/ $563 \mathrm{bp}$ ) to those of $H$. aspergillata CBS 519.91 and C. cinerea (GenBank accession no. MH873955.1). Coprinopsis calospora, the second-matched strain, exhibited $99.1 \%$ similarity (558/563 bp). The ITS sequence of the lung tissue was most closely related to that of $H$. aspergillata CBS 519.91 with $99.5 \%$ identity (221/222 bp). Voriconazole was added to the treatment regimen as soon as the species was identified, as successful treatment with voriconazole has been reported in a few cases [8]. Neutrophils donated by her father were infused once every week for five weeks. Despite liposomal amphotericin B and voriconazole treatment, the fungal infection could not be controlled, and the patient died three weeks later.

$H$. aspergillata is a rare fungal pathogen that may cause lifethreatening infections, particularly in populations with hematologic malignancies [3]. We have described a case wherein $\mathrm{H}$.

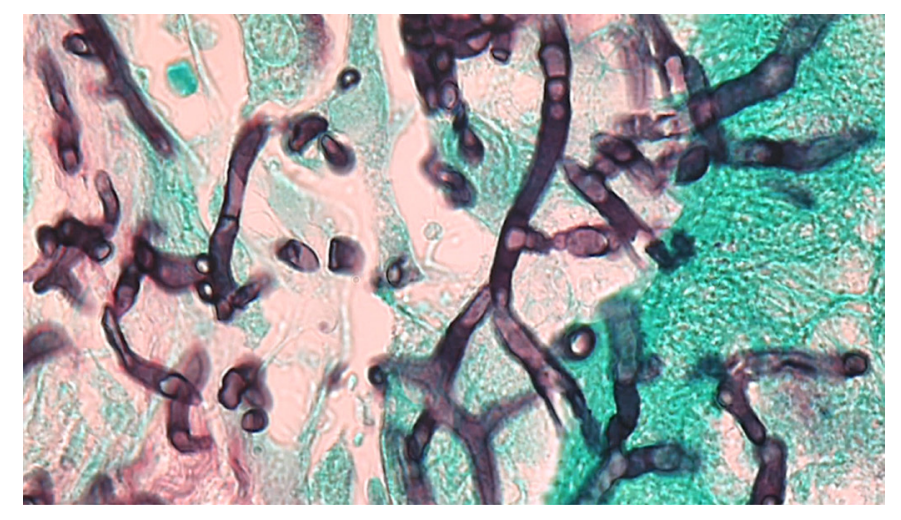

Fig. 2. Gomori-Grocott methenamine silver stain of lung biopsy tissue showing septate hyphae with multi-branching $(\times 1,000)$.

aspergillata was identified from culture-negative lung tissue and pleural fluid specimens. To the best of our knowledge, this is the first reported case of invasive $H$. aspergillata infection in Korea. Direct DNA sequencing using a fresh specimen may be useful, especially when the culture remains sterile. $H$. aspergillata have rarely undergone molecular identification from culture-negative specimens [7, 8]. Negative fungal cultures may be attributed to the use of antifungal agent prior to the microbial cultures, although it is unclear whether caspofungin had antifungal activity against $H$. aspergillata in this case. Many filamentous basidiomycete fungi isolates are sterile in the clinical laboratory, and the lack of key morphologic features, such as sporulation, can further make the identification of the pathogen challenging under microscopic examination $[9,10]$. In our case, the histopathological diagnosis was Aspergillus abscess, based on the microscopic examination of the lung biopsy specimen that revealed fungal infiltration with narrow septate hyphae and multiple branching. The accurate identification of the pathogen, however, was possible using rDNA sequencing.

In conclusion, invasive $H$. aspergillata infections are uncommon and can be fatal. The present case highlighted the usefulness and accuracy of direct DNA sequencing, using a fresh specimen, in identifying the fungal pathogen.

\section{ACKNOWLEDGMENTS}

None.

\section{AUTHOR CONTRIBUTIONS}

Huh HJ conceived and designed the study. Chong E, Yu H, Kim TY, and Huh HJ analyzed the data. Chong E wrote the manu- 
script. Yoo KH, Kim Y, and Lee NY reviewed the manuscript. All authors have accepted their responsibilities for the entire content of this manuscript and approved submission.

\section{CONFLICTS OF INTEREST}

No potential conflicts of interest relevant to this article were reported.

\section{RESEARCH FUNDING}

None declared.

\section{ORCID}

Eunbin Chong
Hui-Jin Yu
Tae Yeul Kim
Keon Hee Yoo
Yae-Jean Kim
Hee Jae Huh
Nam Yong Lee

https://orcid.org/0000-0001-5427-5729 https://orcid.org/0000-0002-7064-1968 https://orcid.org/0000-0002-6405-5305 https://orcid.org/0000-0002-5980-7912 https://orcid.org/0000-0002-8367-3424 https://orcid.org/0000-0001-8999-7561 https://orcid.org/0000-0003-3688-0145

\section{REFERENCES}

1. Speller DE and Maclver AG. Endocarditis caused by a Coprinus species: a fungus of the toadstool group. J Med Microbiol 1971;4:370-4.
2. Moniot M, Lavergne RA, Morel T, Guieze R, Morio F, Poirier P, et al. Hormographiella aspergillata: an emerging basidiomycete in the clinical setting? A case report and literature review. BMC Infect Dis 2020;20:945.

3. Isabel Cristina RS, Diana A, Karen A. Breakthrough Hormographiella aspergillata infection in a patient with acute myeloid leukemia receiving posaconazole prophylaxis: a case report and review. Mycopathologia 2020;185:1069-76.

4. Nanno S, Nakane T, Okamura H, Nishimoto M, Koh H, Nakamae H, et al. Disseminated Hormographiella aspergillata infection with involvement of the lung, brain, and small intestine following allogeneic hematopoietic stem cell transplantation: case report and literature review. Transpl Infect Dis 2016;18:611-6.

5. Chauhan A, Gruenberg J, Arbefeville S, Mettler T, Brent CH, Ferrieri P. Disseminated Hormographiella aspergillata infection with lung and brain involvement after allogenic hematopoietic stem-cell transplantation in a 54-year-old man. Lab Med 2019;50:426-31.

6. Suarez F, Olivier G, Garcia-Hermoso D, Randriamalala E, Ghez D, Bruneau J, et al. Breakthrough Hormographiella aspergillata infections arising in neutropenic patients treated empirically with caspofungin. J Clin Microbiol 2011;49:461-5.

7. Godet C, Cateau E, Rammaert B, Grosset M, Le Moal G, Béraud G, et al. Nebulized liposomal amphotericin $B$ for treatment of pulmonary infection caused by Hormographiella aspergillata: case report and literature review. Mycopathologia 2017;182:709-13.

8. Tschopp J, Perentes JY, Beigelman-Aubry C, Berezowska S, Lovis A Spertini $\mathrm{O}$, et al. Invasive Hormographiella aspergillata infection in patients with acute myeloid leukemia: Report of two cases successfully treated and review of the literature. Med Mycol Case Rep 2021;32:6872.

9. Brandt ME. Filamentous basidiomycetes in the clinical laboratory. Curr Fungal Infect Rep 2013;7:219-23.

10. Lee JM, Han E, Kim J, Park JH, Sung GH, Shin JH, et al. Five Korean cases of respiratory tract infection by filamentous basidiomycetes. Ann Lab Med 2020;40:84-7. 